\title{
Leptospira weilii serovar Topaz, a new member of the Tarassovi serogroup isolated from a bovine source in Queensland, Australia
}

\author{
Correspondence \\ L. D. Smythe \\ Lee_Smythe@health.qld.gov.au
}

\author{
B. G. Corney, ${ }^{1} \dagger$ A. T. Slack, ${ }^{2} \dagger$ M. L. Symonds, ${ }^{2}$ M. F. Dohnt, ${ }^{2}$ \\ C. S. McClintock, ${ }^{3}$ M. R. McGowan ${ }^{3}$ and L. D. Smythe ${ }^{2}$
${ }^{1}$ Animal Research Institute, Queensland Department of Primary Industries and Fisheries, Yeerongpilly, Australia
${ }^{2}$ WHO/FAO/OIE Collaborating Centre for Reference \& Research on Leptospirosis, Western Pacific Region, Communicable Diseases, Queensland Health Forensic and Scientific Services, Brisbane, Australia \\ ${ }^{3}$ University of Queensland, St Lucia, Australia
}

Leptospirosis is a disease caused by members of the genus Leptospira and is considered to be an emerging zoonotic disease of global importance (Bharti et al., 2003). In Australia, there have been 7507 notifications of the disease since 1934 and $57.6 \%$ of these notifications have occurred in the state of Queensland (Slack et al., 2006a).

Two streams of taxonomy are concurrently used for Leptospira; species level identification based upon DNADNA hybridization and serological identification using the similarity of cell-wall antigens as determined by using the cross-agglutinin absorption test (CAAT). Seventeen species have been described (Brenner et al., 1999; Levett et al., 2006; Perolat et al., 1998; Yasuda et al., 1987) and over 200 serovars have been identified worldwide (Levett, 2001). In addition to the aforementioned taxonomy systems, serovars are grouped into serogroups. Although serogroups

†These authors contributed equally to this work and wish to be recognized as joint first authors.

Abbreviations: CAAT, cross-agglutinin absorption test; MAT, microscopic agglutination test.

The GenBank/EMBL/DDBJ accession numbers for the $16 \mathrm{~S}$ rRNA and gyrB gene sequences of Leptospira weilii serovar Topaz strain 94$79970 / 3$ are DQ483058 and DQ483059, respectively. have no official taxonomic status, they remain as a practical way of grouping serovars that share common antigens (Kmety \& Dikken, 1993).

Ten serovars from within four species have been identified previously from within Australia with the majority of the serovars being isolated in the state of Queensland. These serovars include Leptospira interrogans serovars Australis, Zanoni, Kremastos, Robinsoni, Broomi, Pomona, Szwajizak, Leptospira kirschneri serovar Valbuzzi, Leptospira weilii serovar Celledoni and Leptospira meyeri serovar Perameles (Kmety \& Dikken, 1993).

This study reports the isolation and identification of a new Leptospira serovar isolated in Australia, using phenotypic, serological and molecular techniques. We determined that this is a unique serovar belonging to the species Leptospira weilii, with serological similarity with members of the Tarassovi serogroup. We propose that the serovar be named Topaz, after the locality of the dairy farm from which the original isolate was obtained.

The isolate, 94-79970/3, was obtained from bovine urine using a culture method as described previously (McClintock et al., 1993). The isolate was forwarded to the WHO/FAO/OIE Collaborating Centre for Reference \& 
Research on Leptospirosis, Brisbane, Australia for further identification. Phenotypic characterization using growth at various temperatures and growth in 8-azaguanine was performed as described by Johnson \& Rogers (1964) and Perolat et al. (1998).

Hyperimmune antiserum against strain 94-79970/3 was produced in rabbits using a method described by Graves \& Faine (1970). Serological identification of the isolates was performed using the microscopic agglutination test (MAT) method with serovars representative of the major Leptospira serogroups (Faine et al., 1999). The Leptospira serogroups tested included: Icterohaemorrhagiae, Javanica, Celledoni, Canicola, Ballum, Pyrogenes, Cynopteri, Autumnalis, Djasiman, Australis, Pomona, Grippotyphosa, Hebdomadis, Mini, Sejroe, Bataviae, Tarassovi, Panama, Shermani and Semeranga. Where a significant titre was found against a serogroup, screening was then done using all available serovars within that serogroup. CAAT was performed to determine whether the unknown isolate was similar to that serovar (Kmety et al., 1970).

DNA extracts were prepared from strain $94-79970 / 3$ and $16 \mathrm{~S}$ rRNA and DNA gyrase subunit B ( gyrB) gene amplification/ sequencing was performed as described previously (Slack et al., 2006b). Sequences from strain 94-79970/3 and representative sequences from members of the genus Leptospira were aligned using CLUSTAL W (Thompson et al., 1994). Estimates of evolutionary divergence between sequences analyses were conducted using the Jukes-Cantor method in MEGA4 (Jukes \& Cantor, 1969; Tamura et al., 2007). Codon positions included were $1 \mathrm{st}+2 \mathrm{nd}+3 \mathrm{rd}+$ non-coding. All positions containing gaps and missing data were eliminated from the dataset. A total of 1290 positions were used in the $16 \mathrm{~S}$ rRNA gene sequence analysis and a total of 405 positions for the $\operatorname{gyr} B$ gene sequence analysis. A phylogenetic tree was constructed from the aligned $16 \mathrm{~S}$ rRNA gene sequences using the neighbour-joining method (Saitou \& Nei, 1987), bootstrapped 1000 times and rooted using Leptonema illini serovar Habaki strain Habaki as an outgroup.

The isolate, 94-79970/3, was cultured from the urine of a heifer on a dairy farm near the town of Topaz on the Atherton Tableland in Queensland, Australia in August 1994. The heifer had two MATs performed prior to urine collection: a baseline test in April 1994 that was negative for all Leptospira serovars and a second test in June 1994, which gave a titre of $1: 100$ to the serogroup Tarassovi. The herd had been established 12 months prior to the study commencing and the leptospirosis vaccination history of the herd was unknown at the time of the study. This work was part of a University of Queensland, longitudinal study of patterns of Leptospira infections in north Queensland dairy herds with an emphasis on zoonotic infections. The laboratory support for the study was provided by Queensland Department of Primary Industries and Fisheries and Queensland Health.

When isolate 94-79970/3 was screened serologically against reference hyperimmune antisera of the common serogroups found in Australia, titres were produced against the Tarassovi $(1: 1600)$ and Bataviae $(1: 100)$ serogroups. When the culture and hyperimmune sera for isolate 94-79970/3 were tested against the reference strains of the Tarassovi serogroup (Table 1), there were no significant reactions as compared with the control reaction of 94-79970/3 antisera vs 94-79970/ 3 culture. To confirm these results, CAAT reactions were performed against 94-79970/3 using Leptospira borgpetersenii serovar Tarassovi and $L$. weilii serovar Celledoni, as these two serovars have been previously identified in Australia (Slack et al., 2006a) and gave less than $10 \%$ similarity (results not shown).

Phenotypically, strain $94-79970 / 3$ grew at $30{ }^{\circ} \mathrm{C}$, but failed to grow at $13{ }^{\circ} \mathrm{C}$ or in the presence of 8 -azaguanine. Species identification was performed using $16 \mathrm{~S}$ rRNA and gyrB gene sequencing. The $16 \mathrm{~S}$ rRNA gene sequence similarity between strain 94-79970/3 and the 17 previously described Leptospira was found to be in the range $89-99.69 \%$. L. weilii (99.69\%), L. borgpetersenii (99.46\%) and Leptospira noguchii (99.2\%) showed the highest level of $16 \mathrm{~S}$ rRNA gene similarity to strain 94-79970/3. As there is a high level of similarity between $16 \mathrm{~S}$ rRNA genes of Leptospira, this result was confirmed using gyrB sequence analysis. The range of similarity using gyrB gene sequences was much greater than that using the $16 \mathrm{~S}$ rRNA gene (79.7-100\%), with L. weilii (100\%) showing the highest level of similarity. Phylogenetic analysis using aligned $16 \mathrm{~S}$ rRNA gene sequences showed that strain 94-79970/3 was placed within the radiation of the genus Leptospira and within the clade formed by the pathogenic Leptospira, which includes $L$. weilii.

The isolate was forwarded to the WHO/FAO/OIE Collaborating Centre for Reference \& Research on Leptospirosis, Royal Tropical Institute, Amsterdam, The Netherlands, for confirmation and for storage within their culture collection. These data were presented to and recommended by the subcommittee on the taxonomy of Leptospiraceae (Levett \& Smythe, 2006).

\section{Short description of Leptospira weilii serovar Topaz}

L. weilii serovar Topaz strain 94-79970/3 was isolated from a urine culture taken from a heifer in the locality of Topaz in far Northern Queensland, Australia. Phenotypically, $L$. weilii serovar Topaz strain $94-79970 / 3$ grows at $30{ }^{\circ} \mathrm{C}$ in Ellinghausen McCullough Johnson Harris (EMJH) medium, but failed to grow at $13{ }^{\circ} \mathrm{C}$ in EMJH medium or in the presence of 8 -azaguanine. The isolate was found to be a unique serovar as confirmed by the CAAT. Strain 94$79970 / 3$ was identified as a member of the species L. weilii by $16 \mathrm{~S}$ rRNA and gyrB gene sequencing. The reference strain for this serovar is $94-79970 / 3$ and is held in the culture collections of the WHO/FAO/OIE Collaborating Centre for Reference \& Research on Leptospirosis, Royal Tropical Institute, Amsterdam, The Netherlands (KIT 9479970/3) and WHO/FAO/OIE Collaborating Centre for Reference \& Research on Leptospirosis, Western Pacific Region, Brisbane, Australia (94-79970/3=LT722). 
Table 1. MAT results for L. weilii serovar Topaz strain 94-79970/3 against the cultures and antisera of the Tarassovi serogroup

\begin{tabular}{|c|c|c|c|c|}
\hline \multirow[t]{2}{*}{ Leptospira species } & \multirow[t]{2}{*}{ Serovar } & \multirow[t]{2}{*}{ Strain } & \multicolumn{2}{|c|}{ Titre } \\
\hline & & & $\begin{array}{c}94-79970 / 3 \text { vs reference } \\
\text { antisera }\end{array}$ & $\begin{array}{l}\text { Reference culture vs } \\
94-79970 / 3 \text { antisera }\end{array}$ \\
\hline L. borgpetersenii & Tarassovi & Perepelitsin & 200 & 200 \\
\hline L. borgpetersenii & Kisuba & Kisuba & 100 & 800 \\
\hline L. santarosai & Bakeri & LT79 & 1600 & 200 \\
\hline L. santarosai & Atchafalaya & LSU 1013 & 400 & 200 \\
\hline L. santarosai & Bravo & Bravo & 800 & 800 \\
\hline L. santarosai & Rama & 316 & 100 & 200 \\
\hline L. borgpetersenii & Tunis & $\mathrm{P} 2 / 65$ & 400 & 400 \\
\hline L. inadai & Kaup & LT64-68 & $<100$ & Not performed \\
\hline L. santarosai & Darien & $637 \mathrm{~K}$ & Not performed & 400 \\
\hline L. santarosai & Gatuni & $1473 \mathrm{~K}$ & 800 & 400 \\
\hline Unknown & Banna & A 31 & Not performed & 800 \\
\hline Unknown & Gengma & M48 & 1600 & 400 \\
\hline L. weilii & Langati & M 39090 & Not performed & 200 \\
\hline L. weilii & Mogdeni & Compton 746 & Not performed & 800 \\
\hline L. borgpetersenii & Yunxian & L 100 & Not performed & 800 \\
\hline L. weilii & Topaz & $94-79970 / 3$ & $>6400$ & $>6400$ \\
\hline
\end{tabular}

\section{Acknowledgements}

The authors also wish to thank Queensland Health and the Queensland Department of Primary Industries and Fisheries for their past and present support of leptospirosis research in Australia and to acknowledge the support of the Dairy Research and Development Corporation for the original study.

\section{References}

Bharti, A. R., Nally, J. E., Ricaldi, J. N., Matthias, M. A., Diaz, M. M., Lovett, M. A., Levett, P. N., Gilman, R. H., Willig, M. R. \& other authors (2003). Leptospirosis: a zoonotic disease of global importance. Lancet Infect Dis 3, 757-771.

Brenner, D. J., Kaufmann, A. F., Sulzer, K. R., Steigerwalt, A. G., Rogers, F. C. \& Weyant, R. S. (1999). Further determination of DNA relatedness between serogroups and serovars in the family Leptospiraceae with a proposal for Leptospira alexanderi sp. nov. and four new Leptospira genomospecies. Int J Syst Bacteriol 49, 839-858.

Faine, S., Adler, B. \& Bolin, C. (1999). Leptospira and leptospirosis. Melbourne, Australia: MediSci.

Graves, S. \& Faine, S. (1970). Antileptospiral agglutinins produced in rabbits. Bull World Health Organ 43, 579-587.

Johnson, R. C. \& Rogers, P. (1964). Differentiation of pathogenic and saprophytic Leptospires with 8-azaguanine. J Bacteriol 88, 1618-1623.

Jukes, T. H. \& Cantor, C. R. (1969). Evolution of protein molecules. In Mammalian Protein Metabolism, pp. 21-132. Edited by H. N. Munro. New York: Academic Press.
Kmety, E. \& Dikken, H. (1993). Classification of the species Leptospira interrogans and history of its serovars, 1st edn. Groningen, Netherlands: University Press Groningen.

Kmety, E., Galton, M. M. \& Sulzer, C. R. (1970). Further standardization of the agglutinin-absorption test in the serology of leptospires. Bull World Health Organ 42, 733-738.

Levett, P. N. (2001). Leptospirosis. Clin Microbiol Rev 14, 296-326.

Levett, P. N. \& Smythe, L. (2006). International Committee on Systematics of Prokaryotes Subcommittee on the taxonomy of Leptospiraceae. Minutes of the closed meeting, 12 and 13 November 2005, Chiang Mai, Thailand. Int J Syst Evol Microbiol 56, 20192020.

Levett, P. N., Morey, R. E., Galloway, R. L. \& Steigerwalt, A. G. (2006). Leptospira broomii sp. nov., isolated from humans with leptospirosis. Int J Syst Evol Microbiol 56, 671-673.

McClintock, C. S., McGowan, M. R., Corney, B. G., Colley, J., Smythe, L., Dohnt, M. \& Woodrow, M. (1993). Isolation of Leptospira interrogans serovars hardjo and zanoni from a dairy herd in north Queensland. Aust Vet J 70, 393-394.

Perolat, P., Chappel, R. J., Adler, B., Baranton, G., Bulach, D. M., Billinghurst, M. L., Letocart, M., Merien, F. \& Serrano, M. S. (1998). Leptospira fainei sp. nov., isolated from pigs in Australia. Int J Syst Bacteriol 48, 851-858.

Saitou, N. \& Nei, M. (1987). The neighbor-joining method: a new method for reconstructing phylogenetic trees. Mol Biol Evol 4, 406425.

Slack, A. T., Symonds, M. L., Dohnt, M. F. \& Smythe, L. D. (2006a). The epidemiology of leptospirosis and the emergence of Leptospira 
borgpetersenii serovar Arborea in Queensland, Australia, 1998-2004. Epidemiol Infect 134, 1217-1225.

Slack, A. T., Symonds, M. L., Dohnt, M. F. \& Smythe, L. D. (2006b). Identification of pathogenic Leptospira species by conventional or real-time PCR and sequencing of the DNA gyrase subunit B encoding gene. BMC Microbiol 6, 95.

Tamura, K., Dudley, J., Nei, M. \& Kumar, S. (2007). MEGA4: Molecular Evolutionary Genetics Analysis (MEGA) software version 4.0. Mol Biol Evol 24, 1596-1599.
Thompson, J. D., Higgins, D. G. \& Gibson, T. J. (1994). CLUSTAL W: improving the sensitivity of progressive multiple sequence alignment through sequence weighting, position-specific gap penalties and weight matrix choice. Nucleic Acids Res 22, 4673-4680.

Yasuda, P. H., Steigerwalt, A. G., Sulzer, K. R., Kaufmann, A. F., Rogers, F. \& Brenner, D. J. (1987). Deoxyribonucleic acid relatedness between serogroups and serovars in the family Leptospiraceae with proposals for seven new Leptospira species. Int J Syst Bacteriol 37, 407415. 